\title{
The extended running W-plasty: an additional tool for simultaneous reduction of the hypertrophied labia minora and redundant clitoral hood
}

\author{
Hamdy A. Elkhatib \\ Plastic and Hand Surgery Department, Alkhor Hospital, Doha 00974, Qatar. \\ Correspondence to: Dr. Hamdy A. Elkhatib, Plastic and Hand Surgery Department, Alkhor Hospital, B.O. 3050, Doha 00974, Qatar. \\ E-mail: hamdya24@yahoo.com
}

How to cite this article: Elkhatib HA. The extended running W-plasty: an additional tool for simultaneous reduction of the hypertrophied labia minora and redundant clitorial hood. Plast Aesthet Res 2016;3:359-63.

Article history:

Received: 28-05-2016

Accepted: 27-10-2016

Published: 22-11-2016

Key words:

Extended W-plasty,

labia minora,

clitoral hood reduction

\begin{abstract}
Aim: The extended running W-plasty technique using the W-plasty principle is a modification of the conventional technique. The use of this technique was utilized for simultaneous reduction of the protuberant labia minora and the redundant clitoris. Methods: Twenty-three patients presented to the plastic surgery clinic between 2008 and 2015 with the complaints of protuberant and enlarged labia minora in conjunction with a hypertrophied clitorial hood. The extended running W-plasty was performed in all patients. Surgery was performed under general anesthesia as an outpatient procedure with a range of operative time from 30-45 min. The Likert scale was used to evaluate outcomes. Results: Patients maintained labial length with decreased scarring. Small hematomas occurred in 2 patients and were treated conservatively. One case of wound dehiscence occurred and was also treated conservatively. Patients returned to normal activity 5-7 days postoperatively. The cosmetic outcome of all patients was very satisfactory. Conclusion: The running W-plasty technique is ideal for closure of secondary defects following excision of both the redundant labia minora and clitoral hood, while maintaining length and providing tensionless scars. The technique conserves the original tissues while avoiding over- or under- resection of the labia.
\end{abstract}

\section{INTRODUCTION}

Repeated tearing and stretching caused by childbirth, aging, and sexual intercourse, in addition to congenital defects such as vaginal atresia and Müllerian agenesis, and gender switching play a role in the request to change the size of the labia minora. ${ }^{[1]}$ Congenital hypertrophy of the labia minora has also been reported. ${ }^{[2]}$ Maas and $\mathrm{Hage}^{[3]}$ reported the use of a W-shaped resection of the protuberant labia minora in 13 patients. Later, Solanki et al. ${ }^{[4]}$ applied the same technique to 12 patients. Both groups of authors noted that the running

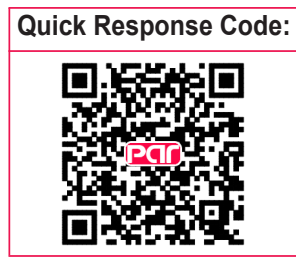




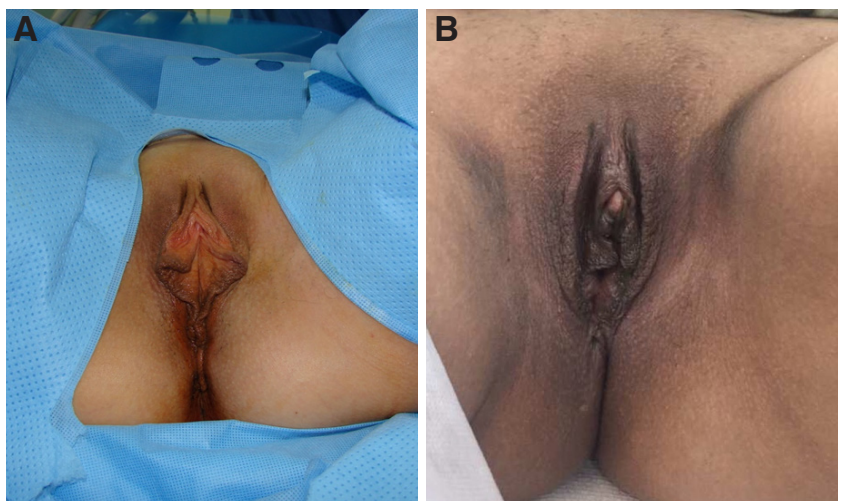

Figure 1: (A) A 34-year-old female with bilateral hypertrophy of the labia minora and a redundant clitoral hood; (B) A 27-year-old female with bilateral incomplete hypertrophy of the labia minora and a redundant clitoral hood

W-shaped resection technique avoids many potential problems which can occur with other techniques. Capraro $^{[5]}$ introduced the edge resection technique in which the labia is resected at its free edges. Hamori ${ }^{[6]}$ preserved the natural rugosity by performing the central wedge technique. De-epithelialization is another tool which has been used to reduce the size of the labia, and can be performed with either a scalpel ${ }^{[7]}$ or the $\mathrm{CO}_{2}$ laser. ${ }^{[8]}$ Gonzalez et al. ${ }^{[9]}$ reported the use of the custom flask labiaplasty technique in 50 patients, which permits precise reduction of the labia minora. Ostrzenski ${ }^{[10]}$ described a fenestration labiaplasty technique in which the inferior flap is transposed to reduce the height and width of the labia.

The primary goal of the extended running W-plasty technique, described in this study, is to achieve an acceptable protrusion of both the labia minora and the clitoral hood beyond the labia majora. The design reported in this study is a modification of the conventional $\mathrm{W}$-plasty reported in the literature which is used for reduction only of the hypertrophied labia minora.

\section{METHODS}

Six patients with unilateral hypertrophy and 17 patients with bilateral hypertrophy of the labia minora presented for evaluation [Figure 1].

Within this group, 8 patients complained of irritation and chronic infection while the remaining 15 patients were concerned with the noticeable protrusion of the enlarged labia minora and its associated psychological and emotional distress.

Patients were admitted to the same day surgery unit after a complete examination. General endotracheal anesthesia was used in all patients. The procedure commenced with marking the running $\mathrm{W}$-plasty on both sides of labia minora with an extension through the clitoral hood [Figure 2]. Excision of the predetermined amount of tissue was performed [Figure 3], followed by meticulous hemostasis and closure of the interdigitating small triangular flaps with absorbable 4-0 monofilament [Figures 4 and 5].

A compression dressing was applied for several hours and removed prior to discharge. At the postoperative visits, an outcome evaluation questionnaire based on a 5-point Likert scale was administered. The questionnaire evaluated the level of improvement in physical exercise, improvement in sexual intercourse, improvement in appearance and shape of the labia minora and clitoral hood, elimination of fungal infection, ability of patients to wear fitted undergarments, and improvement in sense of well-being.

A 5-point Likert scale was designed with options of 1 (very dissatisfied), 2 (dissatisfied), 3 (moderately satisfied), 4 (satisfied), and 5 (highly or very satisfied).

The preoperative and postoperative photos were analyzed based on the extent of external genitalia exposure and analysis was performed by an independent
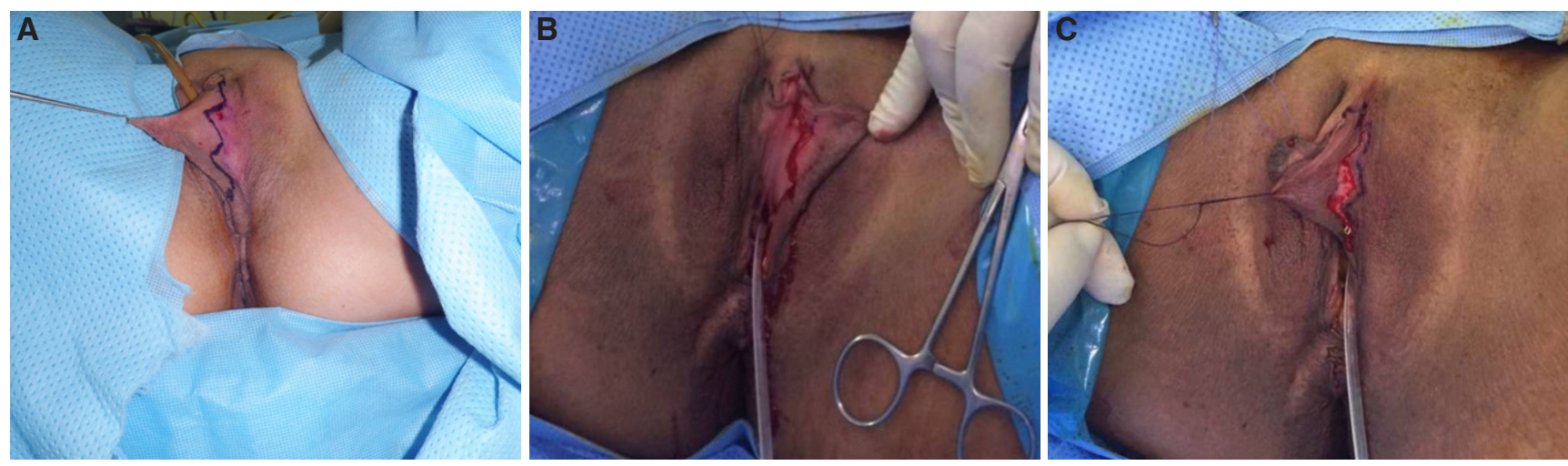

Figure 2: (A) A 34-year-old female, marked for an extended running W-plasty; (B and C) A 27-year-old female, marked with an extended running $\mathrm{W}$-plasty on both sides of the labia minora 


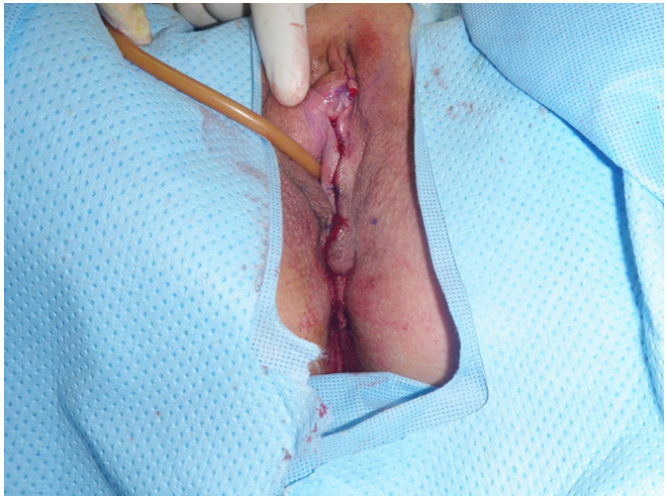

Figure 3: A 34-year-old female, appearance of the labia minora after reduction. Note the interdigitating triangles. The excision extended to involve the clitoral hood

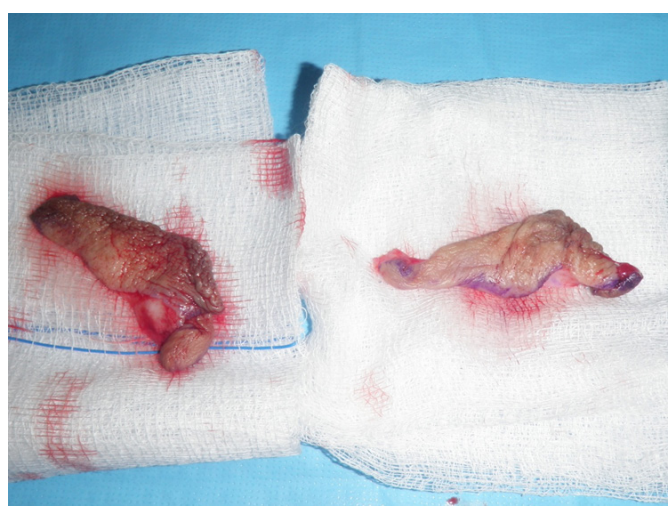

Figure 4: Tissue excised from both labia minora (the 34-year-old female)

plastic surgeon.

\section{RESULTS}

Because the W-plasty technique conserves tissue, over-resection was avoided, and the shape and size of the labia minora were acceptable in all patients. In addition, the vertical length of the labia was preserved. All patients were noted to have symmetry with a and natural color and contour of their labia minora [Figure 6].

Small hematomas occurred in one patient and were treated conservatively. Wound dehiscence $(1-2 \mathrm{~cm}$ in length) developed in one patient and was also treated conservatively [Table 1].

Based on the results of the Likert scale and the evaluation questionnaire [Table 2] provided during the follow-up period, the aesthetic outcomes were very satisfactory in all patients. Patients experienced improvement in their daily activities, including sexual intercourse and physical exercise. Hygiene became easier, and patients stated that they did not need to apply antifungals or local steroids after surgery. All patients were able to wear bathing suits without embarrassment. No patients experienced scar
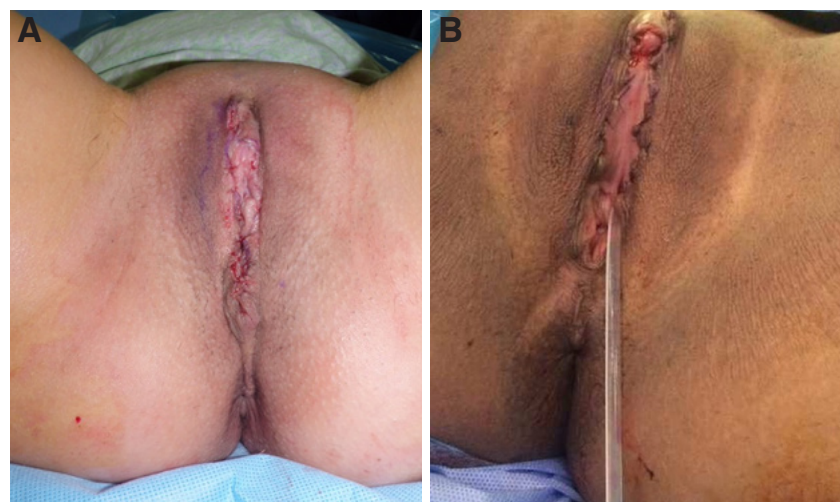

Figure 5: Immediate postoperative view of the 34-year-old female (A) and the 27-year-old female (B). The procedure is completed by suturing the interdigitating small flaps

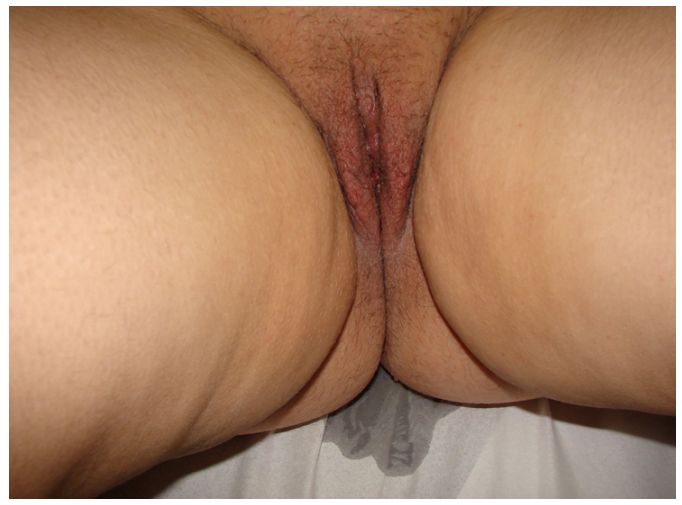

Figure 6: One-year postoperative result of the 34-year-old female

numbness, sensitivity, or scar pain during intercourse.

\section{DISCUSSION}

The use of the extended running W-plasty technique is required for the simultaneous reduction of hypertrophied labia minora and prominent clitoral hood. The central wedge resection removes a full-thickness wedge of skin from the thickest portion of the labia minora. ${ }^{[11]}$ Giraldo et al. ${ }^{[12]}$ add a 90 -degree Z-plasty to the central wedge procedure; this modification produces a refined surgical scar that is less tethered and has less tension. The W-plasty previously described by Maas and Hage ${ }^{[3]}$ and Solanki et al ${ }^{[4]}$ is limited as it does not simultaneously address the redundant hood of the clitoris.

The technique described in the current report addresses both the hypertrophied labia and clitoral hood with an appropriate skin resection. The extended $W$-plasty has the same principles of the conventional W-plasty in thatthe angles of the "W" vary between 50 and 55 degrees, but are further extended to involve another aesthetic unit which includes the defect resulting from the reduction of the enlarged clitoris. The technique divides the scar into small triangles to break up the scar contracture and providing a more 
Table 1: Patient profile

\begin{tabular}{|c|c|c|c|c|c|c|}
\hline No. & $\begin{array}{c}\text { Age } \\
\text { (years) }\end{array}$ & Clinical findings & Procedure & Complications & $\begin{array}{l}\text { Follow-up } \\
\text { (months) }\end{array}$ & Outcome \\
\hline 1 & 27 & $\begin{array}{l}\text { Unilateral hypertrophied labia minora and } \\
\text { hypertrophied clitoral hood }\end{array}$ & Extended W-plasty & None & 30 & Very satisfied \\
\hline 2 & 30 & $\begin{array}{l}\text { Bilateral hypertrophied labia minora and } \\
\text { hypertrophied clitoral hood }\end{array}$ & $\begin{array}{l}\text { Bilateral extended } \\
\text { W-plasty }\end{array}$ & None & 29 & Very satisfied \\
\hline 3 & 35 & $\begin{array}{l}\text { Bilateral hypertrophied labia minora and } \\
\text { hypertrophied clitoral hood }\end{array}$ & $\begin{array}{l}\text { Bilateral extended } \\
\text { W-plasty }\end{array}$ & Small hematoma & 22 & Very satisfied \\
\hline 4 & 38 & $\begin{array}{l}\text { Unilateral hypertrophied labia minora and } \\
\text { hypertrophied clitoral hood }\end{array}$ & Extended W-plasty & None & 13 & Very satisfied \\
\hline 5 & 41 & $\begin{array}{l}\text { Bilateral hypertrophied labia minora and } \\
\text { hypertrophied clitoral hood }\end{array}$ & $\begin{array}{l}\text { Bilateral extended } \\
\text { W-plasty }\end{array}$ & $\begin{array}{l}\text { Wound dehiscence } \\
\text { of } 1-2 \mathrm{~cm}\end{array}$ & 31 & Very satisfied \\
\hline 6 & 22 & $\begin{array}{l}\text { Bilateral hypertrophied labia minora and } \\
\text { hypertrophied clitoral hood }\end{array}$ & $\begin{array}{l}\text { Bilateral extended } \\
\text { W-plasty }\end{array}$ & None & 14 & Very satisfied \\
\hline 7 & 29 & $\begin{array}{l}\text { Unilateral hypertrophied labia minora and } \\
\text { hypertrophied clitoral hood }\end{array}$ & Extended W-plasty & None & 36 & Very satisfied \\
\hline 8 & 40 & $\begin{array}{l}\text { Bilateral hypertrophied labia minora and } \\
\text { hypertrophied clitoral hood }\end{array}$ & $\begin{array}{l}\text { Bilateral extended } \\
\text { W-plasty }\end{array}$ & None & 13 & Very satisfied \\
\hline 9 & 36 & $\begin{array}{l}\text { Unilateral hypertrophied labia minora and } \\
\text { hypertrophied clitoral hood }\end{array}$ & Extended W-plasty & None & 12 & Very satisfied \\
\hline 10 & 30 & $\begin{array}{l}\text { Bilateral hypertrophied labia minora and } \\
\text { hypertrophied clitoral hood }\end{array}$ & $\begin{array}{l}\text { Bilateral extended } \\
\text { W-plasty }\end{array}$ & None & 15 & Very satisfied \\
\hline 11 & 33 & $\begin{array}{l}\text { Bilateral hypertrophied labia minora and } \\
\text { hypertrophied clitoral hood }\end{array}$ & $\begin{array}{l}\text { Bilateral extended } \\
\text { W-plasty }\end{array}$ & None & 12 & Very satisfied \\
\hline 12 & 22 & $\begin{array}{l}\text { Bilateral hypertrophied labia minora and } \\
\text { hypertrophied clitoral hood }\end{array}$ & $\begin{array}{l}\text { Bilateral extended } \\
\text { W-plasty }\end{array}$ & None & 12 & Very satisfied \\
\hline 13 & 29 & $\begin{array}{l}\text { Unilateral hypertrophied labia minora and } \\
\text { hypertrophied clitoral hood }\end{array}$ & Extended W-plasty & None & 27 & Very satisfied \\
\hline 14 & 25 & $\begin{array}{c}\text { Bilateral hypertrophied lasbia minora and } \\
\text { hypertrophied clitoral hood }\end{array}$ & $\begin{array}{l}\text { Bilateral extended } \\
\text { W-plasty }\end{array}$ & None & 12 & Very satisfied \\
\hline 15 & 26 & $\begin{array}{l}\text { Bilateral hypertrophied labia minora and } \\
\text { hypertrophied clitoral hood }\end{array}$ & $\begin{array}{l}\text { Bilateral extended } \\
\text { W-plasty }\end{array}$ & Small hematoma & 29 & Very satisfied \\
\hline 16 & 30 & $\begin{array}{l}\text { Bilateral hypertrophied labia minora and } \\
\text { hypertrophied clitoral hood }\end{array}$ & $\begin{array}{l}\text { Bilateral extended } \\
\text { W-plasty }\end{array}$ & None & 22 & Very satisfied \\
\hline 17 & 29 & $\begin{array}{l}\text { Bilateral hypertrophied labia minora and } \\
\text { hypertrophied clitoral hood }\end{array}$ & $\begin{array}{l}\text { Bilateral extended } \\
\text { W-plasty }\end{array}$ & None & 12 & Very satisfied \\
\hline 18 & 33 & $\begin{array}{l}\text { Bilateral hypertrophied labia minora and } \\
\text { hypertrophied clitoral hood }\end{array}$ & $\begin{array}{l}\text { Bilateral extended } \\
\text { W-plasty }\end{array}$ & None & 14 & Very satisfied \\
\hline 19 & 44 & $\begin{array}{l}\text { Unilateral hypertrophied labia minora and } \\
\text { clitoral hood }\end{array}$ & Extended W-plasty & None & 33 & Very satisfied \\
\hline 20 & 48 & $\begin{array}{l}\text { Bilateral hypertrophied labia minora and } \\
\text { hypertrophied clitoral hood }\end{array}$ & $\begin{array}{l}\text { Bilateral extended } \\
\text { W-plasty }\end{array}$ & None & 31 & Very satisfied \\
\hline 21 & 40 & $\begin{array}{l}\text { Bilateral hypertrophied labia minora and } \\
\text { hypertrophied clitoral hood }\end{array}$ & $\begin{array}{l}\text { Bilateral extended } \\
\text { W-plasty }\end{array}$ & None & 12 & Very satisfied \\
\hline 22 & 30 & $\begin{array}{c}\text { Bilateral hypertrophied labia minora and } \\
\text { hypertrophied clitoral hood }\end{array}$ & $\begin{array}{l}\text { Bilateral extended } \\
\text { W-plasty }\end{array}$ & None & 21 & Very satisfied \\
\hline 23 & 29 & $\begin{array}{l}\text { Unilateral hypertrophied labia minora and } \\
\text { hypertrophied clitoral hood }\end{array}$ & Extended W-plasty & None & 12 & Very satisfied \\
\hline
\end{tabular}

Small hematoma is defined as less than $2 \mathrm{~cm}$. LM: labia minora; $\mathrm{CH}$ : clitoral hood

level surface to the scar.

In the current study, the most common reason for seeking reduction of the labia minora (13 out of 20 patients) was dissatisfaction with the appearance of the labial and clitoral hood. Hong et al. ${ }^{[13]}$ reported the use of both the central wedge resection and asymmetric Z-plasty techniques in order to avoid the linear scar. De-epithelialization of the skin $^{[14]}$ of the central region of the medial and lateral aspects of each labia minora reduces the excess vertical tissue, while preserving natural rugosity and the sensory and erectile abilities of the labia. One disadvantage of de-epithelialization is that the width of the individual labia can increase if a large area of labial tissue is de-epithelialized. Although de-epithelialization by laser treatment has been reported ${ }^{[15]}$ it presents the potential for the occurrence of epidermal inclusion cysts. Closure of the opposing W-shaped incisions results in a tensionless zigzag suture line running obliquely across the edge of the labium.

In this study, the running $\mathrm{W}$-shaped resection technique avoids many potential problems which 
Table 2: Summary of 5-point Likert scale

\begin{tabular}{|c|c|c|c|c|c|}
\hline Questionnaire & Very satisfied & Satisfied & Unsatisfied & Very unsatisfied & Not sure \\
\hline Improvement of hygiene & All patients & - & - & - & - \\
\hline Improvement of sexual intercourse & All patients & - & - & - & - \\
\hline Painful scar & All patients & - & - & - & - \\
\hline Improvement in appearance and shape & All patients & - & - & - & - \\
\hline Elimination of fungal infection & All patients & - & - & - & - \\
\hline Improvement of physical exercise & All patients & - & - & - & - \\
\hline Improvement in sense of well-being & All patients & - & - & - & - \\
\hline Ability of patients to wear a fitted size & All patients & - & - & - & - \\
\hline
\end{tabular}

can occur with other techniques, including wound contracture and dehiscence. The extended running W-plasty technique is ideal for closure of the secondary defect created following excision of both the redundant labia minora and the redundant clitoral hood because it maintains the vertical length and provides tensionless scars. The reduced labia minora remains sensate and painless. This technique avoids the overor underresection of the labia, and all patients in our series were relieved of the functional problems related to an enlarged labia minora and clitoris.

In conclusion, the extended running W-plasty technique is a viable alternative to the conventional W-plasty, central wedge resection, edge resection, de-epithelialization excision, laser de-epithelialization, and other techniques. It is a modification of the W-plasty design reported in literature, and can be used to simultaneously reduce both the hypertrophied labia minora and the redundant clitoral hood.

\section{Financial support and sponsorship}

None.

\section{Conflicts of interest}

There are no conflicts of interest.

\section{Patient consent}

All patients gave informed consent.

\section{Ethics approval}

The study followed the ethical rules of Alkhor Hospital and was approved.

\section{REFERENCES}

1. Kato K, Kondo A, Gotoh M, Tanaka J, Saitoh M, Namiki Y. Hypertrophy of labia minora in myelodysplastic women. Labioplasty to ease clean intermittent catheterization. Urology 1988;31:294-9.

2. Radman HM. Hypertrophy of the labia minora. Obstet Gynecol 1976;48:S78-9.

3. Maas SM, Hage JJ. Functional and aesthetic labia minora reduction. Plast Reconstr Surg 2000;105:1453-6.

4. Solanki NS, Tejero-Trujeque R, Stevens-King A, Malata CM. Aesthetic and functional reduction of the labia minora using the Maas and Hage technique. J Plast Reconstr Aesthet Surg 2010;63:1181-5.

5. Capraro VJ. Congenital anomalies. Clin Obstet Gynecol 1971;14:9881012.

6. Hamori CA. Aesthetic labia minora and clitoral hood reduction using extended central wedge resection. Plast Reconstr Surg 2009;124:337; author reply 337-8.

7. Choi HY, Kim KT. A new method for aesthetic reduction to the labia minora (the deepithelialized reduction labioplasty). Plast Reconstr Surg 2000;105:419-22; discussion 423-4.

8. Pardo J, Solà V, Ricci P, Guilloff E. Laser labioplasty of labia minora. Int J Gynaecol Obstet 2006;93:38-43.

9. Gonzalez F, Dass D, Almeida B. Custom flask labiaplasty. Ann Plast Surg 2015;75:266-71.

10. Ostrzenski A. Fenestration labioreduction of the labium minus: a new surgical intervention concept. ISRN Obstet Gynecol 2014;2014:671068.

11. Alter GJ. Aesthetic labia minora and clitoral hood reduction using extended central wedge resection. Plast Reconstr Surg 2008;122:1780-9.

12. Giraldo F, Gonzalez C, de Haro F. Central wedge nymphectomy with a 90-degree Z-plasty for aesthetic reduction of the labia minora. Plast Reconstr Surg 2004;113:1820-5; discussion 1826-7.

13. Hong ZJ, Wang J, Yuan SM, Wang Y, Hu XB, Jiang HQ. Central wedge resection and asymmetric Z-plasty for minor labia reduction. Zhonghua Zheng Xing Wai Ke Za Zhi 2009;25:268-70. (in Chinese)

14. Cao YJ, Li FY, Li SK, Zhou CD, Hu JT, Ding J, Xie LH, Li Q. A modified method of labia minora reduction: the deepithelialised reduction of the central and posterior labia minora. $J$ Plast Reconstr Aesthet Surg 2012;65:1096-102.

15. Oranges CM, Sisti A, Sisti G. Labia minora reduction techniques: a comprehensive literature review. Aesthet Surg J 2015;35:419-31. 